\title{
Spray deposition profiles in pome fruit trees: effects of sprayer design, training system and tree canopy characteristics
}

\author{
Ashenafi T. Duga ${ }^{1}$, Kris Ruysen ${ }^{3}$, Donald Dekeyser ${ }^{2}$, David Nuyttens ${ }^{2}$, Dany Bylemans ${ }^{3}$, Bart \\ M. Nicolai ${ }^{1}$, Pieter Verboven ${ }^{1}$ \\ ${ }^{1}$ KU Leuven, Department of Biosystems, MeBioS, De Croylaan 42, 3001 Leuven, Belgium \\ ${ }^{2}$ Institute for Agricultural and Fisheries Research (ILVO) - Technology and Food Science Unit - \\ Agricultural Engineering, Burg. Van Gansberghelaan 115, 9820 Merelbeke, Belgium \\ ${ }^{3}$ Research Station for Fruit Growing (pcfruit), Department of Ecology, Fruittuinweg 1, 3800 Sint- \\ Truiden, Belgium
}

Corresponding author: Pieter Verboven, KU Leuven, Department of Biosystems, MeBioS, De Croylaan 42, 3001 Leuven, Belgium; Email: pieter.verboven@biw.kuleuven.be; Tel.: +32 (0) 1632 1453, Fax. : +32 (0) 16322966

\begin{abstract}
Air assisted orchard sprayers are characterized by a strong airflow that carries the pesticide droplets to the target canopy and assist in moving the plant parts to allow deposition throughout the whole tree. It has been shown before that different designs of orchard sprayers result in different airflow profiles, but it is still unclear whether these differences strongly affect on-target spray distribution, and what is the role of tree architecture. Here we present an in-field analysis of the on-target deposition profiles from three distinct sprayer types in trees of four different apple and pear training systems.
\end{abstract}


The results obtained showed that there was a strong relationship between the vertical leaf deposition profile and the outlet air flow pattern from the sprayers. Stronger air assistance (higher air speed) was directly correlated to a higher on-target deposition. It was also observed that directing nozzles towards the target is always an advantage irrespective of tree architecture. Tree characteristics such as total leaf cover, leaf wall porosity and tree volume strongly affected the total on-target deposition, further confirming previous claims that ground surface area alone is an incorrect measure for dose calculation in fruit trees.

\section{Keywords}

Air flow profile; spray distribution; fully-leafed trees; bare trees; spray application technique

\section{INTRODUCTION}

All plant protection products are applied with the intention of depositing sufficient active materials on the target plant while minimizing off target losses. In orchards, this is achieved using air assisted sprayers. Air assisted orchard sprayers use air jets generated by means of a fan to carry pesticide droplets, to displace the air in the crop canopy and to realize a homogeneous deposition on to the target canopy (Da Silva et al., 2006; Dekeyser et al., 2013; Delele et al., 2005; Escolà et al., 2013; Gupta et al., 2012; Khot et al., 2012; Sidahmed and Brown, 2001; Walklate et al., 1996). The pesticide deposition on the canopy can directly or indirectly be affected by the plant architecture, the physico-chemical properties of the pesticide, the meteorological conditions and the used spraying technique, among others (Catania et al., 2011; Celen et al., 2008; Cross et al., 2001; Dorr et al., 2013; Jaeken et al., 2001; Nuyttens et al., 2009; Pergher and Gubiani, 1995; Rosell and Sanz, 2012; Vallet and Tinet, 2013). In particular, the 
efficacy of air assisted orchard sprayers strongly depends on the magnitude and quality of the air jet generated (Holownicki et al., 2000; Panneton et al., 2005). Sprayers vary in the type of fan generating the air flow, the number and position of fans, nozzle configuration and the type of outlet design directing the airflow to the target and this adds to the complexity of the process to the extent that it is difficult to derive general guidelines for applications.

Tree architecture varies with the training system used. Pruning and training techniques are used in fruit trees to create a strong structural framework that will support heavy fruit loads, achieve better light penetration throughout the canopy and make the trees easier to manage. The plant canopy also provides the necessary environment for the survival and distribution of pests. A heterogeneous distribution of pests is manifested by different tree architectures because of the variation in their micro climatic conditions, availability of resources and suitability for pest control (Blomefield et al., 1997; Pinero and Prokopy, 2005; Simon et al., 2007, 2006). Various canopy shapes have been developed through tree training; each of them having their own light penetration, load carrying capacity and pest distribution. According to the work of (Simon et al., 2006), the centrifugal training system for apple improves canopy porosity to light and shows a significant decrease in pest infestation and pathogen infection compared to training systems such as Vertical Axis or Solaxe. Design of tree architecture has mainly focused on effects of tree training on fruit yield and quality (Costes et al., 2006; Whitting et al., 2005; Lauri and Laurens , 2005). However, tree architecture affects the fate of pesticide droplets inside the plant microenvironment which directly determines the efficacy of the treatment. To this end, new precision spraying application techniques are being developed that incorporate sensing modules to perform tree-specific spraying (Chen et al., 2013; Doruchowski et al., 2011; Escolà et al., 2013; Llorens et al., 2010; Sedlar et al., 2013). Currently, these techniques use one or more tree structure 
characteristics to adjust air assistance and spray flow rate, including canopy height (Moltó et al., 2001), foliage density (Balsari et al., 2009; Doruchowski et al., 2011), ratio of actual canopy width to maximum canopy width (Escolà et al., 2013; Solanelles et al., 2006).

To aid the understanding of which tree characteristics are relevant to the application process in combination with different designs of air-assisted sprayers, this work aimed to assess the ontarget spray distribution in different tree training systems with different spraying techniques. Three-dimensional structure characteristics of 4 training systems (apple classical (also called vertical axe), pear classical (also called bush-spindle), pear T-hedge (also called hedge of Tienen) and pear V-hedge) were measured for bare and fully leafed trees. The on-target deposition from 3 distinct air-assisted sprayers (an axial fan sprayer, a cross-flow sprayer and a sprayer with individual air jets) on the different training systems were compared. Both the spray distribution and total spray deposition were calculated combining deposition values and 3D tree structure data.

\section{MATERIALS AND METHODS}

\subsection{Orchard sprayers}

Three air-assisted orchard sprayers with a different type of air-blast system were considered in this work. The first sprayer was a cross-flow sprayer (DuoProp, BAB Bamps, Sint-Truiden, Belgium) with two axial fans (Fig. 1a). The second type was a classical single axial fan sprayer (Condor V, Hardi, Taastrup, Denmark) (Fig. 1b). The last sprayer (Tango, Hardi, Taastrup, Denmark) was equipped with a centrifugal fan and 5 individual air spouts for each side connected to the air outlet by flexible ducts (Fig. 1c). This sprayer was not tested for the pear Thedge training system. The sprayers were fitted with fully characterized Albuz (Saint-Gobain Solcera, Évreux, France) ATR hollow cone nozzles (Dekeyser et al., 2013). The axial and cross 
flow sprayers were equipped with 16 Albuz ATR orange nozzles of size $0.985 \pm 0.0185$ 1/min and $0.98375 \pm 0.019 \mathrm{l} / \mathrm{min}$ respectively. These nozzles were operating at a pressure of $6.0 \mathrm{bar}$ producing a spray with a volume median diameter (VMD) of $155.8 \mu \mathrm{m}$. The sprayer with individual spouts was equipped with 10 Albuz ATR red nozzles of size $1.506 \pm 0.04219$ 1/min. These nozzles were operating at a pressure of 8 bar producing a spray with a VMD of $176.6 \mu \mathrm{m}$. Before each trial, the liquid flow rate from the nozzles was measured using a mechanical measuring device (A.A.M.S. NV, Maldegem, Belgium). All machines were operated for the same nominal application rate of $500 \mathrm{l} \mathrm{ha}^{-1}$ at a driving speed of $6 \mathrm{~km} \mathrm{~h}^{-1}$ except for the experiment with T-hedge $\left(6.2 \mathrm{~km} \mathrm{~h}^{-1}\right)$.

The vertical profile of the outlet air flow from each sprayer was measured before the deposition trials (Fig. 2). These measurements were performed using a hot wire anemometers (Air velocity transducer, model 8465, TSI, Shoreview, MN, USA) placed as close as possible to the outlets. Additional measurements were done using 3D ultrasonic sensors (model 81000, Young, Traverse City, MI, USA) placed at $0.15 \mathrm{~m}$ perpendicular to the outlet. The air flow from the axial and cross flow sprayers was measured at horizontal interval of $0.05 \mathrm{~m}$ following the contour of the air outlet. For the sprayer with individual spouts, the average of the three measurements that were made at the individual spout outlet was taken. Each sprayer has a typical outlet design and air flow pattern. The total air flow rates were estimated based on the air velocities measured at the air outlet and the corresponding surface area. The axial and cross flow sprayers produced an air volume flow rate of about $50,000 \mathrm{~m}^{3} \mathrm{~h}^{-1}$ whereas the sprayer with individual spouts produced a lower air volume flow rate of about $13,000 \mathrm{~m}^{3} \mathrm{~h}^{-1}$ ((Dekeyser et al., 2013). 


\subsection{Training systems}

In this study, four different training systems were considered, three for pear (Pyrus communis L. cv. Conference) and one for apple (Malus domestica cv. Jored). For each training system, three neighboring trees were characterized. The planting distance was 1 to $1.5 \mathrm{~m}$ and the row distance 3.2 to $3.5 \mathrm{~m}$, depending on the training system. The pear classical (bush-spindle) training system consisted of one central stem and 3 to 5 bigger branches located at about 0.5 to $1 \mathrm{~m}$ from the ground. These branches were guided to grow upright along the row. Both the central stem and bigger branches had several smaller sub-branches and were supported by a wooden stalk. The classical pear trees used for this experiment were nine-year old trees (Fig. 3). The height of the trees was $3.40 \pm 0.11 \mathrm{~m}$.

The pear T-hedge (hedge of Tienen) training system also had one central stem on which other branches were guided to grow sideways along the row making a T-shape. Both the central stem and the bigger branches on the stem had sub-branches that mostly grew upright. Nine-year old pear T-hedge trees with one main vertical branch and 10 side branches in the spindle form were used in this experiment (Fig. 3). The T-hedges had a height of $3.27 \pm 0.09 \mathrm{~m}$.

The pear V-hedge trees had one central stem on which exactly 2 branches were growing on each side of the row. These branches had very few sub-branches by pruning. The 4 branches were supported by 4 bamboo canes that were fixed at the center of the row and inclined to the direction of the branch that they were supporting. Two of the bamboo canes that were on opposite side of the row from the central stem were more or less fixed on the same position on the ground and inclined across both sides of the row. The growth of the branches in these trees was guided parallel to the rows using wires and pruning to give a V-shaped profile (Fig. 3). The V-hedge reached $2.75 \pm 0.1 \mathrm{~m}$ high. 
The vertical axe (apple classical) training system had one big central stem with randomly distributed small branches. The central stems of these older apple trees were mostly not straight. In most cases the branches were mainly one level branches except a few bigger ones with secondary branches or sub-branches. The classical apple trees mostly had more hanging branches than branches growing upright. This could be due to the small thickness of the branches, which were sensitive to bending when they bear fruits. The apple trees used for this experiment were 21-year old trees having one main vertical branch with numerous weaker fruiting branches. These classic apple trees were $3.30 \pm 0.14 \mathrm{~m}$ high.

\subsection{Deposition measurement}

Deposition measurements were performed in an experimental orchard field (pcfruit vzw, SintTruiden, Belgium) in October 2010 on the fully leafed trees immediately after harvest and in March 2011 on bare trees. The three trees of each training system were sprayed one-sided. The measurement protocol was in accordance to the ISO standard (ISO 22522, 2007) and used metal tracers which were collected on $12 \mathrm{~cm}^{2}$ filter papers (Whatman Int Ltd, No.1). Three metal tracers, potassium $\left(\mathrm{KNO}_{3}\right)$ for the experiment with Duoprop, zinc $\left(\mathrm{Zn}\left(\mathrm{NO}_{3}\right)_{2} \cdot 4 \mathrm{H}_{2} \mathrm{O}\right)$ for the experiment with CondorV and magnesium $\left(\mathrm{Mgcl}_{2} \cdot 6 \mathrm{H}_{2} \mathrm{O}\right)$ for the experiment with Tango were used during the trials. The filter papers were attached to the sampling positions as rigid as possible using paper clips or pushpins. The three trees were divided into sampling zones according to their height, width and depth. There were seven zones along the height of the tree,

three zones across the depth and two along the row (one at the stem and one between two consecutive trees). The dimension of the sampling zones (each $0.5 \mathrm{~m}$ ) was the same for all training systems and each zone had three samplers. Three trees were sampled for each training system and repetitions throughout this analysis refers to the number of trees sampled. 
The samples were collected and stored at $4{ }^{\circ} \mathrm{C}$ in dark after the trials. The metal tracers were then extracted from the filter paper by washing the samplers with $0.16 \mathrm{M} \mathrm{HNO}_{3}$ for 15 minutes. The amount of tracer collected was calculated from the concentration measured with a Varian SpectrAA 300 atomic absorption spectrometer. The deposition was determined as the amount of active substance collected per unit area $\left(\mathrm{g} \mathrm{cm}^{-2}\right)$. There was a difference in the tank concentration between the three sprayer types. Tank concentrations of $1579 \mathrm{ppm}$ for the experiment with CondorV, 1411 ppm for the experiment with Duoprop and 1683 ppm for the experiment with Tango were measured during the experiment on the fully leafed trees. These concentrations were 1444 ppm for the experiment with CondorV, 1658 ppm for the experiment with Duoprop and $1678 \mathrm{ppm}$ for the experiment with Tango during the experiment on bare trees. The results presented were corrected for the variations in tank concentration and driving speed. Wind speed and direction, temperature and relative humidity were also measured at $10 \mathrm{~m}$ height (Tables 1 4).

\section{4. $3 D$ tree structure and leaf area}

Leaf area density (LAD) as a function of tree height was calculated using the photographic gap fraction method based on angular images of all three fully leaved trees of each training system. See (Phattaralerphong and Sinoquet, 2005) and (Phattaralerphong et al., 2006) for details of the method and (Endalew et al., 2009) for its application.

The internode coordinates and diameter of the stems and branches were measured for the three trees used in the field experiment. A 3D geometric model of the trees was then constructed using the measurements and representation method developed by (Endalew et al., 2006). A detailed porous sub-domain was added around all the main branches of the tree to model the effect of very thin and short branches, leaves, flowers and other parts which were not considered in the 
canopy architecture. This resulted in a volumetric representation of the leaf cover for all the trees. Combining the leaf area density and tree volume data, the average total leaf area $\left(\mathrm{m}^{2}\right)$ per height zone of $0.5 \mathrm{~m}$ was calculated for each training system (Fig. 4).

The following tree characteristics were measured and tabulated (average \pm standard deviation): tree height, max. tree width, average to maximum width ratio, total tree volume, tree porosity, leaf wall area porosity, number of branches, and average tree LAD. The tree porosity was defined as the ratio of pore space to the space occupied by branches and leaves. It was determined using the leaf area index (LAI) (Bréda, 2003). The LAI was calculated as the ratio of the total one sided leaf area to the ground area under the tree. The leaf wall area porosity was the fraction of pore space in the total vertical leaf wall area.

\subsection{Statistical analysis}

JMP Pro 11 (SAS Institute Inc., Cary, North Carolina, USA) was used to do the statistical analysis. A significance level of $p<0.05$ was used to check statistical significance. The Shapiro Wilk normality test was done to check if the deposition data was normally distributed. This test and the histogram distribution showed that it was right-skewed $(\mathrm{W} \leq 0.82, \mathrm{p}<0.05)$. The data were then transformed using base-10 logarithm and square root and checked again for normality. The highest $\mathrm{W}$ value $(\mathrm{W} \geq 0.98, \mathrm{p}<0.05)$ was obtained for the base-10 logarithm transformation and this was used for the statistical test. Factorial ANOVAs and Tukey post-hoc tests were done for each parameter combinations to check for statistical significance. 


\section{RESULTS}

\subsection{Tree structure of different training systems}

Figure 5 shows the frontal (parallel to the tree row) and lateral (across the tree row) views of the 3D structure of the 4 training systems used in the experiment. The first two figures (Fig. 5a and 5b) show the frontal and lateral views of the apple classical training system, respectively. This training system is characterized by a relatively uniform leaf cover and had the largest tree volume among the 4 training systems. It had a one sided total leaf area of $4.35 \mathrm{~m}^{2}$ and $1.85 \mathrm{~m}^{3}$ tree volume.

Figures $5 \mathrm{c}$ and $5 \mathrm{~d}$ show the frontal and lateral views of the pear classical training system, respectively. Pear classical had the smallest one sided total leaf cover area $\left(2.05 \mathrm{~m}^{2}\right.$, less than half of that of apple) and most of the branches and leaves were clustered in the lower part of the tree (Fig. 3b). It also had the smallest tree volume $\left(0.73 \mathrm{~m}^{3}\right.$, again less than half of that of apple).

The pear V-hedge (Fig. 5e and 5f) had the largest LAD $\left(3.46 \mathrm{~m}^{-1}\right)$ and was characterized by a dense cluster of leaves in a relatively small tree volume. It had a $0.74 \mathrm{~m}^{3}$ tree volume, similar to that of the pear classical, and a total leaf area of $2.67 \mathrm{~m}^{2}$, higher than that of pear classical. The difference in the leaf area density of the 4 training systems was statistically significant $(\mathrm{p}=$ $0.003)$.

The last two figures (Fig. 5g and 5h) show the lateral and frontal views of the Pear T-hedge training system. It had the largest total leaf area $\left(4.42 \mathrm{~m}^{2}\right.$, only slightly higher than that of apple). It had a volume of $1.63 \mathrm{~m}^{3}$.

Table 5 summarizes the tree characteristics that are used in the deposition analysis. The tree height was measured to the top of the tree zone depicted in Figure 5. The pear V-hedge was the 
shortest $(2.75 \mathrm{~m})$ of the four training systems. All the others were taller than $3.2 \mathrm{~m}$. Pear classical had the highest trees and the largest tree width $(3.4 \mathrm{~m}$ and $1.75 \mathrm{~m}$ respectively), and also the most non-uniform width (average to max. width ratio of 0.41 ). The maximum tree width was restricted to a small portion at the bottom of the tree height and, hence, resulted in a small tree volume for the classical pear system. Pear T-hedge had the lowest value of maximum tree width (1.05 m).

The tree porosity was highest for the classical pear system and smallest for apple and T-hedge systems. Pear classical had the highest tree porosity and leaf wall area porosity (0.84 and 0.26 respectively), indicating this training system to be the most open of the four.

The theoretical $100 \%$ deposition was the target dose obtained assuming a uniform leaf deposition. It is the estimated deposition per unit leaf area if the spray volume deposits on the leaves uniformly. It is calculated based on the tank concentration, the application rate $\left(5001 \mathrm{~h}^{-1}\right)$, the driving speed $\left(6.2 \mathrm{~km} \mathrm{~h}^{-1}\right)$, the total two side leaf area of the trees and the planting and row distance. It was interesting to see that pear classical had the highest target dose rate although it had the largest tree. It is a consequence of the small tree volume, intermediate LAD and large row and planting distance of this planting system. This result is an indication of the discrepancy between the target dose calculated using the ground surface application rate and the actual amount needed based on the canopy parameters. This is further detailed in the following section.

\subsection{Analysis of vertical deposition for different training systems and sprayers}

Figure 6 presents the measured vertical deposition profiles in different training systems for the different machines, averaged from 3 repetitions (standard deviations are not shown to improve readability of the plots). The profiles are shown at different depths in the canopy (front, middle, 
back). Note that for the V-hedge system only two depths were measured (front and back; for the T-hedge no depth profile was measured, this profile is shown in Figure 7c). In general, we found that the deposition decreases with distance into the tree. It is believed that two sided spraying improves the spray coverage throughout the tree and significantly decreases the difference in deposition across the tree depth compared to a single sided spraying. The profiles for each machine and planting system are generally similar at different depths into the tree. The vertical profiles are difficult to interpret from this figure. Therefore, we have chosen to present the volume-averaged profiles as a function of height.

Figure 7 presents these deposition profiles for the different combinations of training systems and sprayer types. The profiles are average values with standard deviation of deposition per unit leaf area volume-averaged over $0.5 \mathrm{~m}$ high horizontal layers of the trees. In addition to the measured profiles, the plot contains the theoretical 100\% deposition value (Table 5).

Figures 8 and 9 present the fraction of deposited spray on leaves and branches for fully leafed and bare trees for the different training systems and sprayer types. Below, the results are presented and discussed per training system in sections 3.2.1 to 3.2.4.

\subsubsection{Apple classical}

The vertical deposition profile in the apple classical training by the three sprayers is shown in Fig. 7a. Tango (the sprayer with individual spouts) gave the highest deposition at the bottom of the tree (up to a height of $2 \mathrm{~m}$ ) followed by the CondorV axial sprayer and the Duoprop crossflow sprayer. Tango gave a deposition that is even higher than the theoretical target deposition up to a height of $0.5 \mathrm{~m}$. The deposition decreased with increasing height from $1.5 \mathrm{~m}$ to the top of the tree. This can be explained using the vertical velocity profile of the outlet air 
flow and nozzle arrangement for the three sprayer designs (Fig. 1d). The Tango sprayer has a high air jet velocity magnitude up to a height of $2 \mathrm{~m}$ that is maintained furthest from the machine outlet, compared to the other sprayers (Fig. 2c). This will result in deeper penetration in the denser part of the canopy between 1 and $2 \mathrm{~m}$ height (Fig. 6). Above $1.5 \mathrm{~m}$, the air is projected further to the top because of the relatively upward inclination of the top two spouts (Fig. 2c). The individual spouts of the sprayer were always adjusted prior to the trials to the best of our ability to cover the tree heights but the adjustments were done without measurements. There are also other parameters affecting the air jets and it is difficult to exactly position the air jet within the tree height even if the spouts are placed at the their optimal position. This causes the spray from the top nozzles to be drifted away and, hence, we observe a strong decrease in deposition in the higher part of the tree. The outlet velocity of the CondorV sprayer approaches that of the Tango. However, this does not result in as high deposition. This is because of the formation of a poorly targeted large radial plume of air at the outlet of the CondorV sprayer (Fig. 2b), of which the velocity magnitude decays faster with distance from the sprayer, compared to the Tango.

In the top of the tree, we found, on average, a higher deposition with the CondorV compared to Tango. The somewhat lower but more uniform air velocity at the tree from the CondorV appears to be beneficial for deposition in less dense regions such as the top. It should be noted that the $4.5 \mathrm{~m} / \mathrm{s}$ wind that was blowing in the spraying direction during the experiment with CondorV (Table 1) was opposite to the wind during the experiment with Duoprop and Tango sprayers (5.4 and $5.3 \mathrm{~m} / \mathrm{s}$, respectively), that was against the spraying direction. The directed air outlets of the Tango sprayer help in concentrating the spray spectrum on dedicated regions of the canopy. 
The Duoprop crossflow sprayer, due to its ability to provide air assistance in the top region of the canopy (Fig. 2a), also gave higher deposition in the top of the tree than Tango. Tango in general gave a significantly higher average leaf deposition than CondorV and Duoprop $(\mathrm{p}=0.001)$.

The Duoprop sprayer rendered a more uniform deposition than the other sprayers over the height of the tree because of the presence of nozzles regularly arranged at a higher height than the other sprayers and the more uniform velocity profile generated (Fig. 1d and 2a). Consistent with the leaf deposition results, the Tango and CondorV sprayers in general gave a higher branch deposition than the Duoprop sprayer in the lower part of the tree where the tree is denser (not shown). The Duoprop sprayer also had significantly higher deposition at the top. The deposition on the branches was higher than that on the leaves, which is believed to be related to the fact that fluttering leaves are less efficient in capturing droplets than the trunk and branches (Ghosh, 1995). As the observed branch deposition patterns were similar for the other training systems, this analysis of vertical deposition profiles on branches was not repeated for the other training systems.

Compared to the total theoretical target, all machines produced lower deposition. Tango gave the highest total leaf deposition followed by the Duoprop sprayer and then the CondorV sprayer (Fig. 8a). Comparing the difference in total leaf deposition between these sprayers, the Tango sprayer deposited $67 \%$ of the total amount sprayed on the leaf while the CondorV and Duoprop gave a total leaf deposition of only $43 \%$ and $45 \%$, respectively, under the prevailing wind conditions.

All the three sprayer designs gave an equal total branch deposition of about $20 \%$ of the total amount sprayed for the fully leafed trees (Fig. 8a). It thus appears that the Tango sprayer is most 
efficient in total deposition, with $87 \%$ on the target, while the other two sprayers have difficulty in reaching $70 \%$ on target deposition. The relatively higher air volume flow rate generated by the Duoprop and CondorV sprayers carried the spray further through the trees resulting in a higher drift. The much lower air flow rate (one third of the amount generated by Duoprop and CondorV) from the small fans of Tango deposited most of the spray on the trees.

For the bare trees, on average the highest total branch deposition (more than $40 \%$ of the spray volume) is obtained for the Duoprop sprayer followed closely by the Tango. The CondorV gave the lowest branch deposition with less than $30 \%$ on target (Fig. 9a). The presence of leaves reduces the branch deposition with 10 (CondorV) to 30\% (Duoprop). The vertical deposition profile on the bare trees of the three sprayer designs follows the same trend as the fully leafed trees, but have significantly higher areal deposition values.

\subsubsection{Pear classical}

The pear classical training system was in general characterized by very sparse branches and leaves for most of the tree height (Fig. 3). The leaves were clustered only on a small portion of the tree in the lower region (Fig. 4b). Pear classical in general had a 50\% smaller leaf cover area and larger leaf wall porosity (Table 5) than the apple classical training system for most of the tree height. As a consequence, the theoretical target dose is much higher than for apple (Fig. 7a and b). At the same ground surface application rate, the target dose for this pear system is more than double that of apple. Nonetheless, we did not find a higher on-target deposition in this training system.

Regardless of the differences in tree architecture, some characteristics of the vertical deposition profiles on pear are comparable to the ones in apple trees (Fig. 7b). First, the Tango had the 
largest deposition in the lower part of the tree, and the smallest deposition in the top. The canopy distribution of this sprayer seems to be rather independent of canopy type (consider also the Vhedge in Fig. 7c, discussed below). Second, Duoprop and CondorV had higher depositions in the top. The difference in the average leaf deposition over the whole tree was statistically significant when Tango and Duoprop were compared to CondorV ( $\mathrm{p}=0.005$ and 0.04 , respectively) but this was not the case for Duoprop and Tango $(\mathrm{p}=0.11)$. Duoprop did have a less uniform profile in this training system, as compared to apple, with a peak deposition at $2 \mathrm{~m}$ height. The leaf area in this region was 3 to 4 times smaller in pear than in apple (Fig. 4), but this only affected the Duoprop sprayer.

The fractional on-target deposition for this training system was considerably lower than for apple. In general, Tango gave the highest total leaf and branch deposition (46\% of the total amount sprayed) followed by Duoprop depositing $40 \%$ of the total amount sprayed. CondorV gave the lowest on target deposition (27\% of the total amount sprayed) (Fig. 8b). The CondorV sprayer also had lower penetration capacity than the other two sprayers (Fig. 6b). For this training system, the wind was blowing in the direction of the spray for all sprayer types, so differences in deposition could not be attributed to environmental effects (Table 2).

The directed spouts (and nozzles) in the Tango sprayer still produced the highest leaf and branch deposition which shows that directed arrangement of the nozzles is always an advantage irrespective of the leaf area density (Fig. 8b). The advantage of this sprayer, however, is more significant in the more dense apple trees.

In terms of the total branch deposition, Duoprop and Tango gave the highest deposition for both the fully leafed and bare trees (Fig. 9b). But the difference in the average deposition was not 
statistically significant $(\mathrm{p}=0.51,0.32$ and 0.65 for CondorV-Duoprop, CondorV-Tango and Duoprop-Tango respectively).

\subsubsection{Pear V-hedge}

The architecture of the V-hedge training system is characterized by a relatively dense cluster of leaves on the two sides of the V-shape and an open structure in between (Fig. 5f). The leaf area profile resembles that of the apple classical training systems (Fig. 4c), and is more uniform than that of the classical pear system. The total leaf area, however, is smaller than for apple trees (Table 5).

Comparing the vertical leaf deposition profile on (Fig. 7c) for the three sprayer designs, not surprisingly we see the same trend as for the apple and pear classical training systems, with the Tango sprayer outstanding the deposition in the lower region of the canopy but with decreasing deposition to the top. Also here, the Duoprop produced a peak deposition at $2 \mathrm{~m}$ height, and had a less uniform distribution than in apple.

The Duoprop sprayer gave a higher leaf deposition than the CondorV sprayer between heights of 1.5 and $2.5 \mathrm{~m}$, but the difference in the overall average leaf deposition was not statistically significant $(\mathrm{p}=0.44)$. The Tango sprayer gave higher leaf deposition than both CondorV and Duoprop sprayers below $1.5 \mathrm{~m}$. In terms of the overall average leaf deposition, Tango and Duoprop sprayers gave a significantly higher deposition than the CondorV sprayer for this training system $(\mathrm{p}=0.03$ and $\mathrm{p}=0.01$ respectively). The Tango and Duoprop deposited $61 \%$ of the total amount sprayed on the tree, followed by the CondorV sprayer having an on target deposition of $51 \%$ of the total amount sprayed (Fig. 8c). The difference in wind conditions during the experiment for the three sprayers on this training system was relatively low (Table 3). 
In terms of the total branch deposition on the fully leafed trees, all the three sprayer designs gave an almost similar branch deposition close to $25 \%$ of the total amount sprayed. For the bare trees, Duoprop and Tango produced a total branch deposition of $40 \%$ while CondorV gave $30 \%$ total branch deposition (Fig. 9c). For bare trees and over the different training systems, the crossflow and individual spouts sprayer outperform the axial sprayer, having an airflow more directed onto the branches. Both sprayers do, however, have distinct deposition profiles on the branches on all training systems (not shown), with the Tango targeting more the bulk of the canopy and the Duoprop more the top.

\subsubsection{Pear T-hedge}

The T-hedge training system has a wide flat architecture with relatively uniform distribution of leaves throughout the tree height (Fig. 3d). This training system is characterized by a very small tree depth and a high total leaf area distributed uniformly throughout the tree height. Only data for Duoprop and CondorV sprayers were collected for the fully leafed trees of this training system.

As can be seen from the vertical leaf deposition profile in Fig. 7d, the Duoprop and CondorV sprayers gave very similar leaf deposition throughout the tree height. Because of the small width of this training system, the difference in air assistance did not significantly affect on-target deposition. Like for the other pear training systems, there is a significant difference between the vertical leaf deposition profile plot of the two sprayer designs and the theoretical $100 \%$ deposition (Fig. 7d). This is due to the very small width of this training system, despite it being very dense, resulting in a significant amount of droplets moving through the canopy. CondorV gave a slightly higher deposition at the top and bottom of the canopy, whereas Duoprop produced slightly higher deposition in the middle region. The uniform distribution of leaves 
throughout the tree height resulted in equal total leaf depositions of 33\% (CondorV) and 29\% (Duoprop) (Fig. 8d). The Duoprop sprayer gave a higher branch deposition than the CondorV sprayer (Fig. 8d). The difference in the average deposition was statistically significant $(\mathrm{p}=0.01)$.

All the three sprayers were compared for bare trees giving the same deposition pattern as the other cases (not shown).

\section{DISCUSSION}

We observed that the lower air volumetric flow rate and directed air outlets of the sprayer with individual spouts help in concentrating the spray spectrum on dedicated denser regions of the canopy. This is in line with the conclusion of (Holownicki et al., 2000). They also observed that the sprayers with directed spouts gave a higher in canopy deposition than the conventional axial and cross flow sprayers. For the axial and cross flow sprayer, the deposition was mostly similar.

The crossflow sprayer gave a higher deposition than the axial sprayer for the training systems that have a relatively open architecture, such as pear classical. The directional airflow pattern onto the canopy clearly has an advantage here. In the more dense canopies, this advantage seems to disappear.

Both crossflow and axial sprayers gave a better deposition in the top of the tree than the sprayer with individual spouts. The lower air flow rates from the small fans of Tango and the relatively open tree architecture in this region have contributed to the decrease in deposition. This sprayer can, however, be adapted to improve uniformity, by adjusting the spout angles, as we have shown in previous work (Dekeyser et al., 2013). This could be important when targeting specific 
pests such as codling moth, which are mostly observed in the upper part of the tree crown (Losel et al., 2002; Simon et al., 2007).

In terms of uniformity, the crossflow sprayer competes with the axial sprayer. The crossflow sprayer produced a peak at mid height of the canopy that is not present for the axial sprayer. We did observe only a small deposition peak on a patternator wall in indoor trials (Dekeyser et al., 2013) at $1.5 \mathrm{~m}$ height, while for the rest the vertical spray profile in this zone was relatively uniform for the cross flow sprayer. The deposition on a static uniform patternator wall, therefore, does not completely resemble the actual deposition process in real canopies, where differences in the vertical deposition are much more pronounced.

It was also possible to relate deposition in the top of the canopy to tree structural characteristics. T-hedge and apple had an average leaf cover of $0.6 \mathrm{~m}^{2}$ above $2.5 \mathrm{~m}$ height, while pear classical and V-hedge had less than $0.3 \mathrm{~m}^{2}$ of leaf. In terms of average deposition, the former two had almost the double coverage of the latter two, using the proper technique.

The other differences in deposition between training systems mainly relate to the global rather than the local characteristics of the trees, such as volume, total leaf cover and leaf wall porosity, that rendered significantly lower on-target deposition as a fraction of applied dose for the pear classical system. The pear classical tree system is a very open and variable system that appears difficult to cover well. As a result, this system showed the largest discrepancy between theoretical deposition and actual deposition.

In addition to the above parameters, canopy width plays a role in efficient deposition. This became clear when comparing apple classical and pear T-hedge that have the most distinct tree 
width. The latter has considerably lower on-target deposition due to its limited width. Spray assistance could possibly be reduced here to prevent droplets being blown through the canopy.

Using the tree structural characteristics, we have shown that ground surface application rate translates in significantly different leaf application rates. A three-fold difference between classical apple and pear canopies was obtained. Between the pear training systems, the differences were up to two-fold, confirming that ground surface area is an incorrect measure for dose calculation in fruit trees (Walklate and Cross, 2013, 2012; Walklate et al., 2011). The results of this study further show that the total on-target deposition was strongly correlated to the total leaf (branch) area, the tree porosity and tree volume. It can thus be said that dose calculations based on the target surface area (leaf wall area corrected for porosity) would be more effective in determining the amount of spray need for a given canopy. The effect of variation in tree volume can be taken in to account by adjusting the spraying parameters (air assistance and nozzle arrangement).

One set of variables that could not be controlled during the experiments were the climate conditions. Wind was quite variable during the trials and could have increased or decreased differences between machines or training systems. In order to assess such effects, a modeling approach using computational fluid dynamics will be helpful (Delele et al., 2007; A. M. Endalew et al., 2010; A.M. Endalew et al., 2010). 
In conclusion, an extensive field experiment was performed in this work to characterize three different designs of air assisted orchard sprayers in terms of the deposition they gave on different canopy architectures. The combined analysis of vertical deposition profiles, airflow patterns and detailed structure characterization of the canopy allowed to better interpret the spray application process.

The results indicate that canopy structure and machine characteristics are determinant factors in the efficacy and uniformity of the application process. With the state of the art techniques analyzed here, however, we did find significant off-target losses up to and exceeding $50 \%$ of the dose could occur. An open low volume canopy architecture is the main reason for this and precision spraying applications, as well as appropriate and dedicated adjustment of the air flow parameters (velocity and direction) will be needed to reduce these losses significantly.

\section{ACKNOWLEDGEMENT}

The financial support of the Institute for the Promotion of Innovation by Science and Technology in Flanders (project IWT 080528) is gratefully appreciated. This research was carried out in the context of the European COST Action FA1106 ('QualiFruit'). 


\section{REFERENCES}

Balsari, P., Marucco, P., Tamagnone, M., 2009. A crop identification system (CIS) to optimise pesticide applications in orchards. Journal of horticultural science and Biotechnology 113116.

Blomefield, T.L., Pringle, K.L., Sadie, A., 1997. Field observations on oviposition of codling moth, Cydia pomonella (Linnaeus) (Lepidoptera: Olethreutidae), in an unsprayed apple orchard in South Africa. African Entomology 5, 319-336.

Bréda, N.J.J., 2003. Ground-based measurements of leaf area index: a review of methods, instruments and current controversies. Journal of experimental botany 54, 2403-17. doi: $10.1093 / \mathrm{jxb} / \mathrm{erg} 263$

Catania, P., Inglese, P., Pipitone, F., Vallone, M., 2011. Assessment of the Wind Influence on Spray Application using an Artificial Vineyard. European Journal of Horticultural Science 76, 102-108.

Celen, I.H., Arin, S., Durgut, M.R., 2008. The effect of air blast sprayer speed on the chemical distribution in vineyard. Pakistan Journal of Biological Sciences 11, 1472-1476.

Chen, Y., Ozkan, H.E., Zhu, H., Derksen, R.C., Krause, C.R., 2013. Spray Deposition inside Tree Canopies from a Newly Developed Variable-Rate Air-Assisted Sprayer. Transactions of the ASABE 56, 1263-1272. doi:10.13031/trans.56.9839

Costes, E., Lauri, P.., Regnard, J.L., 2006. Analyzing Fruit Tree Architecture: Implications for Tree Management and Fruit Production, in: Horticultural Reviews. pp. 1-61.

Cross, J. V, Walklate, P.J., Murray, R.A., Richardson, G.M., 2001. Spray deposits and losses in different sized apple trees from an axial fan orchard sprayer : 2 . Effects of spray quality 20 .

D.Whitting, M., Lang, G.L., Ophardt, D., 2005. Rootstock and Training System Affect Sweet Cherry Growth, Yield, and Fruit Quality. HortScience 40, 582-586.

Da Silva, A., Sinfort, C., Tinet, C., Pierrat, D., Huberson, S., 2006. A Lagrangian model for spray behaviour within vine canopies. Journal of Aerosol Science 37, 658-674. doi:10.1016/j.jaerosci.2005.05.016

Dekeyser, D., Duga, A.T., Verboven, P., Endalew, A.M., Hendrickx, N., Nuyttens, D., 2013. Assessment of orchard sprayers using laboratory experiments and computational fluid dynamics modelling. Biosystems Engineering 114, 157-169.

doi:10.1016/j.biosystemseng.2012.11.013 
Delele, M. a., Jaeken, P., Debaer, C., Baetens, K., Endalew, a. M., Ramon, H., Nicolaï, B.., Verboven, P., 2007. CFD prototyping of an air-assisted orchard sprayer aimed at drift reduction. Computers and Electronics in Agriculture 55, 16-27.

doi:10.1016/j.compag.2006.11.002

Delele, M.A., De Moor, A., Sonck, B., Ramon, H., Nicolaï, B.M., Verboven, P., 2005. Modelling and Validation of the Air Flow generated by a Cross Flow Air Sprayer as affected by Travel Speed and Fan Speed. Biosystems Engineering 92, 165-174. doi:10.1016/j.biosystemseng.2005.05.018

Dorr, G.J., Hewitt, A.J., Adkins, S.W., Hanan, J., Zhang, H., Noller, B., 2013. A comparison of initial spray characteristics produced by agricultural nozzles. Crop Protection 53, 109-117. doi:10.1016/j.cropro.2013.06.017

Doruchowski, G., Swiechowski, W., Godyn, a., Holownicki, R., 2011. Automatically controlled sprayer to implement spray drift reducing application strategies in orchards. Journal of fruit and ornamental plant research 19, 175-182.

Endalew, A.M., Debaer, C., Rutten, N., Vercammen, J., Delele, M.A., Ramon, H., Nicolaï, B.M., Verboven, P., 2010. A new integrated CFD modelling approach towards air-assisted orchard spraying - Part II: Validation for different sprayer types. Computers and Electronics in Agriculture 71, 137-147. doi:10.1016/j.compag.2009.11.007

Endalew, A.M., Debaer, C., Rutten, N., Vercammen, J., Delele, M.A., Ramon, H., Nicolaï, B.M., Verboven, P., 2010. Modelling the Effect of Tree Foliage on Sprayer Airflow in Orchards. Boundary-Layer Meteorology 138, 139-162. doi:10.1007/s10546-010-9544-6

Endalew, A.M., Hertog, M., Gebrehiwot, M.G., Baelmans, M., Ramon, H., Nicolaï, B.M., Verboven, P., 2009. Modelling airflow within model plant canopies using an integrated approach. Computers and Electronics in Agriculture 66, 9-24.

doi:10.1016/j.compag.2008.11.002

Endalew, A.M., Hertog, M., Verboven, P., Baetens, K., Delele, M.A., Ramon, H., Nicolai, B.M., 2006. Modelling airflow through 3d canopy structure of orchards, in: International Advances in Pesticide Applicatio. AAB, pp. 465-472.

Escolà, a., Rosell-Polo, J.R., Planas, S., Gil, E., Pomar, J., Camp, F., Llorens, J., Solanelles, F., 2013. Variable rate sprayer. Part 1 - Orchard prototype: Design, implementation and validation. Computers and Electronics in Agriculture 95, 122-135.

doi:10.1016/j.compag.2013.02.004

Ghosh, M.R., 1995. Concepts of insect control. New Age international publishers, New Delhi.

Gupta, P., Sirohi, N.P.S., Mishra, I.M., 2012. Air flow characteristics of an air-assisted sprayer through horizontal crop canopy. International journal of agricultural and biological engineering 5, 1-6. doi:10.3965/j.ijabe.20120501.001 
Holownicki, R., Doruchowski, G., Godyn, A., Swiechowski, W., 2000. Variation of spray deposit and loss with Air-jet directions applied in orchards. Journal of Agricultural Engineering Research 77, 129-136. doi:10.1006/jaer.2000.0587

Jaeken, P., Vandermersch, M., De Moor, A., Langenakens, J., 2001. Vertical spray distribution and influence on foliar nutrient distribution in fruit trees. Parasitica 57, 99-113.

Khot, L.R., Ehsani, R., Albrigo, G., Larbi, P. a., Landers, A., Campoy, J., Wellington, C., 2012. Air-assisted sprayer adapted for precision horticulture: Spray patterns and deposition assessments in small-sized citrus canopies. Biosystems Engineering 113, 76-85. doi:10.1016/j.biosystemseng.2012.06.008

Lauri P.É. \& Laurens F, 2005. Architectural types in apple, in: Ramdane Dris (Ed.), Crops: Growth, Quality and Biotechnology. World Food Limited, Helsinki, pp. 1300-1314.

Llorens, J., Gil, E., Llop, J., Escolà, a., 2010. Variable rate dosing in precision viticulture: Use of electronic devices to improve application efficiency. Crop Protection 29, 239-248. doi:10.1016/j.cropro.2009.12.022

Losel, P.M., Potting, R.P.., Ebbinghaus, D., Scherkenbeck, J., 2002. Factors affecting the field performance of an attracticide against the Codling moth. Pest management science 58, 1029-1037.

Moltó, E., Martín, B., Gutiérrez, A., 2001. Pesticide Loss Reduction by Automatic Adaptation of Spraying on Globular Trees. Journal of Agricultural Engineering Research 78, 35-41. doi:10.1006/jaer.2000.0622

Nuyttens, D., Taylor, W.A., De Schampheleire, M., Verboven, P., Dekeyser, D., 2009. Influence of nozzle type and size on drift potential by means of different wind tunnel evaluation methods. Biosystems Engineering 103, 271-280. doi:10.1016/j.biosystemseng.2009.04.001

Panneton, B., Lacasse, B., Piché, M., 2005. Effect of Air-jet Configuration on Spray Coverage in Vineyards. Biosystems Engineering 90, 173-184. doi:10.1016/j.biosystemseng.2004.11.001

Pergher, G., Gubiani, R., 1995. The Effect of Spray Application Rate and Airflow Rate on Foliar Deposition in a Hedgerow Vineyard. Journal of Agricultural Engineering Research 61, 205216. doi:10.1006/jaer.1995.1048

Phattaralerphong, J., Sathornkich, J., Sinoquet, H., 2006. A photographic gap fraction method for estimating leaf area of isolated trees: Assessment with 3D digitized plants. Tree physiology $26,1123-36$.

Phattaralerphong, J., Sinoquet, H., 2005. A method for 3D reconstruction of tree crown volume from photographs: assessment with 3D-digitized plants. Tree physiology 25, 1229-42. 
Pinero, J.C., Prokopy, R.., 2005. Spatial and temporal within-canopy distribution of egglaying by plum curculios (Coleoptera: Curculionidae) on apples in relation to tree size. Journal of entomological science 40, 1-9.

Rosell, J.R., Sanz, R., 2012. A review of methods and applications of the geometric characterization of tree crops in agricultural activities. Computers and Electronics in Agriculture 81, 124-141. doi:10.1016/j.compag.2011.09.007

Sedlar, A.D., Bugarin, R.M., Nuyttens, D., Turan, J.J., Zoranovic, M.S., 2013. Quality and efficiency of apple orchard protection affected by sprayer type and application rate. Spanish Journal of Agricultural Research 11, 935-944.

Sidahmed, M.M., Brown, R.B., 2001. Simulation of spray dispersal and deposition from a forestry airblast sprayer - Part I: Air jet mode, in: Transactions of the ASAE. American Society of Agricultural and Biological Engineers, pp. 5-10.

Simon, S., Lauri, P.E., Brun, L., Defrance, H., Sauphanor, B., 2006. Does fruit-tree architecture manipulation affect the development of pests and pathogens? A case study in an organic apple orchard. ournal of Horticultural Science \& Biotechnology 81, 765-773.

Simon, S., Sauphanor, B., Lauri, P., 2007. Control of Fruit Tree Pests through Manipulation of Tree Architecture. Pest Technology 1, 33-37.

Solanelles, F., Escolà, a., Planas, S., Rosell, J.R., Camp, F., Gràcia, F., 2006. An Electronic Control System for Pesticide Application Proportional to the Canopy Width of Tree Crops. Biosystems Engineering 95, 473-481. doi:10.1016/j.biosystemseng.2006.08.004

Vallet, A., Tinet, C., 2013. Characteristics of droplets from single and twin jet air induction nozzles: A preliminary investigation. Crop Protection 48, 63-68. doi:10.1016/j.cropro.2013.02.010

Walklate, P.J., Cross, J.V., 2012. An examination of Leaf-Wall-Area dose expression. Crop Protection 35, 132-134. doi:10.1016/j.cropro.2011.08.018

Walklate, P.J., Cross, J.V., 2013. Regulated dose adjustment of commercial orchard spraying products. Crop Protection 54, 65-73. doi:10.1016/j.cropro.2013.07.019

Walklate, P.J., Cross, J.V., Pergher, G., 2011. Support system for efficient dosage of orchard and vineyard spraying products. Computers and Electronics in Agriculture 75, 355-362. doi:10.1016/j.compag.2010.12.015

Walklate, P.J., Weiner, K.-L., Parkin, C.S., 1996. Analysis of and Experimental Measurements made on a Moving Air-Assisted Sprayer with Two-Dimensional Air-Jets Penetrating a Uniform Crop Canopy. Journal of Agricultural Engineering Research 63, 365-377. doi:10.1006/jaer.1996.0039 
Table 1: Meteorological conditions for the apple classical training system (Wind direction is with respect to the tree row orientation)

\begin{tabular}{|c|c|c|c|c|c|c|c|c|c|c|}
\hline & \multicolumn{2}{|c|}{ RH (\%) } & \multicolumn{2}{|c|}{$\mathrm{T}\left({ }^{\circ} \mathrm{C}\right)$} & \multicolumn{2}{|c|}{$\operatorname{Wind}_{10 \mathrm{~m}}[\mathrm{~m} / \mathrm{s}]$} & \multicolumn{2}{|c|}{ Wind direction $\left(^{\circ}\right)$} & \multicolumn{2}{|c|}{$\mathrm{T}_{10 \mathrm{~m}}\left[{ }^{\circ} \mathrm{C}\right]$} \\
\hline & 2010 & 2011 & 2010 & 2011 & 2010 & 2011 & 2010 & 2011 & 2010 & 2011 \\
\hline CondorV & 71.67 & 63 & 14.63 & 12.8 & 4.54 & 3.17 & -18.70 & 114.53 & 16.81 & 12.87 \\
\hline DuoProp & 74.75 & 58 & 13.97 & 13.4 & 5.39 & 3.64 & 9.61 & 125.09 & 18.15 & 13.81 \\
\hline Tango & 65.33 & 68.5 & 14.33 & 10.8 & 5.29 & 2.28 & 6.89 & 98.98 & 18.32 & 11.40 \\
\hline
\end{tabular}


Table 2 : Meteorological conditions for the pear classical training system (Wind direction is with respect to the tree row orientation)

\begin{tabular}{|c|c|c|c|c|c|c|c|c|c|c|}
\hline & \multicolumn{2}{|c|}{$\overline{\mathrm{RH}}(\%)$} & \multicolumn{2}{|c|}{$\mathrm{T}\left({ }^{\circ} \mathrm{C}\right)$} & \multicolumn{2}{|c|}{$\operatorname{Wind}_{10 \mathrm{~m}}[\mathrm{~m} / \mathrm{s}]$} & \multicolumn{2}{|c|}{ Wind direction $\left(^{\circ}\right)$} & \multicolumn{2}{|c|}{$\mathrm{T}_{10 \mathrm{~m}}\left[{ }^{\circ} \mathrm{C}\right]$} \\
\hline & 2010 & 2011 & 2010 & 2011 & 2010 & 2011 & 2010 & 2011 & 2010 & 2011 \\
\hline CondorV & 71.25 & 48 & 11.09 & 10.8 & 3.31 & 1.42 & 157.43 & 172.41 & 14.29 & 10.76 \\
\hline DuoProp & 71.25 & 58 & 11.09 & 7.9 & 5.42 & 0.58 & 170.62 & 31.13 & 14.64 & 8.98 \\
\hline Tango & 67.75 & 52.5 & 11.74 & 9.8 & 4.18 & 0.31 & 144.49 & -174.89 & 15.02 & 10.03 \\
\hline
\end{tabular}


Table 3 : Meteorological conditions for the pear V-hedge training system (Wind direction is with respect to the tree row orientation )

\begin{tabular}{|c|c|c|c|c|c|c|c|c|c|c|}
\hline & \multicolumn{2}{|c|}{$\mathrm{RH}(\%)$} & \multicolumn{2}{|c|}{$\mathrm{T}\left({ }^{\circ} \mathrm{C}\right)$} & \multicolumn{2}{|c|}{ Wind $_{10 \mathrm{~m}}[\mathrm{~m} / \mathrm{s}]$} & \multicolumn{2}{|c|}{ Wind direction $\left(^{\circ}\right)$} & \multicolumn{2}{|c|}{$\mathrm{T}_{10 \mathrm{~m}}\left[{ }^{\circ} \mathrm{C}\right]$} \\
\hline & 2010 & 2011 & 2010 & 2011 & 2010 & 2011 & 2010 & 2011 & 2010 & 2011 \\
\hline CondorV & 75.83 & 32 & 18.49 & 14.5 & 2.85 & 3.33 & 111.07 & 147.67 & 21.23 & 14.69 \\
\hline DuoProp & 75.83 & 30.8 & 18.49 & 14.7 & 3.54 & 2.96 & 111.56 & 126.47 & 21.56 & 14.83 \\
\hline Tango & 79.5 & 30.5 & 18.59 & 14.8 & 3.22 & 2.56 & 113.35 & 149.94 & 22.35 & 14.94 \\
\hline
\end{tabular}


Table 4 : Meteorological conditions for the pear T-hedge training system (Wind direction is with respect to the tree row orientation)

\begin{tabular}{|c|c|c|c|c|c|c|c|c|c|c|}
\hline & \multicolumn{2}{|c|}{ RH (\%) } & \multicolumn{2}{|c|}{$\mathrm{T}\left({ }^{\circ} \mathrm{C}\right)$} & \multicolumn{2}{|c|}{ Wind $_{10 \mathrm{~m}}[\mathrm{~m} / \mathrm{s}]$} & \multicolumn{2}{|c|}{ Wind direction $\left(^{\circ}\right)$} & \multicolumn{2}{|c|}{$\mathrm{T}_{10 \mathrm{~m}}\left[{ }^{\circ} \mathrm{C}\right]$} \\
\hline & 2010 & 2011 & 2010 & 2011 & 2010 & 2011 & 2010 & 2011 & 2010 & 2011 \\
\hline CondorV & 81.25 & 43 & 15.77 & 11.6 & 1.67 & 0.75 & 130.97 & -101.72 & 19.16 & 11.99 \\
\hline DuoProp & 88.42 & 39.5 & 14.56 & 12.2 & 3.16 & 0.48 & 115.57 & -12.32 & 19.26 & 12.33 \\
\hline Tango & - & 36.5 & - & 12.9 & - & 1.12 & - & 55.78 & - & 12.48 \\
\hline
\end{tabular}


Table 5 : Characteristics of the three trees used for the field experiment (average $+/$ - standard deviation)

\begin{tabular}{|c|c|c|c|c|}
\hline & $\begin{array}{l}\text { Apple } \\
\text { classical }\end{array}$ & $\begin{array}{l}\text { Pear } \\
\text { classical }\end{array}$ & $\begin{array}{l}\text { Pear } \\
\text { V-hedge }\end{array}$ & $\begin{array}{l}\text { Pear } \\
\text { T-hedge }\end{array}$ \\
\hline Tree height $[\mathrm{m}]$ & $3.30 \pm 0.14$ & $3.40 \pm 0.11$ & $2.75 \pm 0.10$ & $3.27 \pm 0.09$ \\
\hline Max. tree width $[\mathrm{m}]$ & $1.50 \pm 0.26$ & $1.75 \pm 0.37$ & $1.75 \pm 0.14$ & $1.05 \pm 0.38$ \\
\hline Ratio of average to max. tree & $0.71 \pm 0.16$ & $0.41 \pm 0.37$ & $0.81 \pm 0.14$ & $1.0 \pm 0.00$ \\
\hline width & & & & \\
\hline Total single tree volume $\left[\mathrm{m}^{3}\right]$ & $1.85 \pm 0.25$ & $0.73 \pm 0.11$ & $0.74 \pm 0.17$ & $1.63 \pm 0.26$ \\
\hline Tree porosity & $0.47 \pm 0.14$ & $0.84 \pm 0.10$ & $0.59 \pm 0.02$ & $0.48 \pm 0.02$ \\
\hline Leaf wall area porosity & 0.09 & 0.26 & 0.07 & 0.08 \\
\hline Number of branches per tree & $11.0 \pm 2.0$ & $4.0 \pm 1.0$ & $4.0 \pm 0.0$ & $10.0 \pm 0.0$ \\
\hline Average tree $\mathrm{LAD}\left[\mathrm{m}^{-1}\right]$ & $2.35 \pm 0.83$ & $2.82 \pm 0.98$ & $3.61 \pm 1.13$ & $2.71 \pm 0.79$ \\
\hline Row width [m] & 3.25 & 3.50 & 3.20 & 3.50 \\
\hline Planting distance $[\mathrm{m}]$ & 1.00 & 1.50 & 1.00 & 1.50 \\
\hline Total leaf area per tree $\left[\mathrm{m}^{2}\right]$ & $4.35 \pm 0.26$ & $2.06 \pm 0.51$ & $2.67 \pm 0.17$ & $4.42 \pm 0.26$ \\
\hline Total branch area per tree $\left[\mathrm{m}^{2}\right]$ & $1.20 \pm 0.12$ & $2.09 \pm 0.31$ & $1.67 \pm 0.14$ & $1.39 \pm 0.05$ \\
\hline $\begin{array}{l}\text { Theoretical } 100 \% \text { leaf deposition } \\
{\left[1 / \mathrm{cm}^{2}\right]^{*} 10^{-7}}\end{array}$ & $9.34 \pm 0.24$ & $28.8 \pm 0.7$ & $15.1 \pm 0.4$ & $18.2 \pm 0.8$ \\
\hline
\end{tabular}




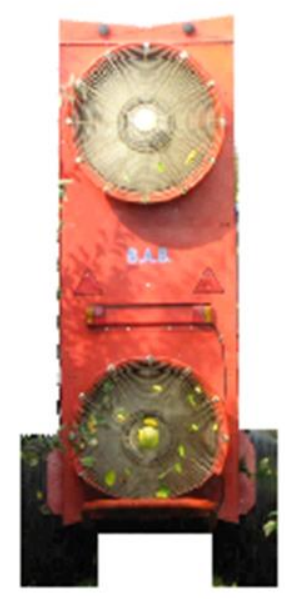

(a)

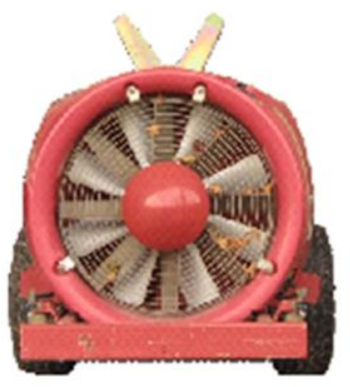

(b)

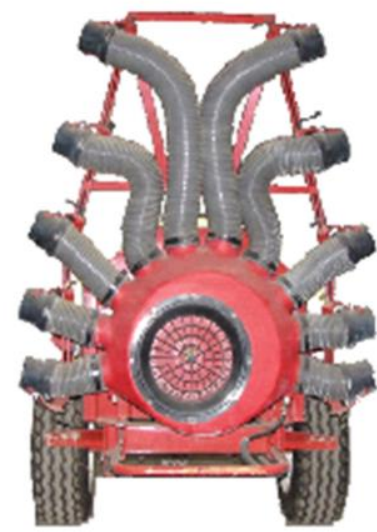

(c)

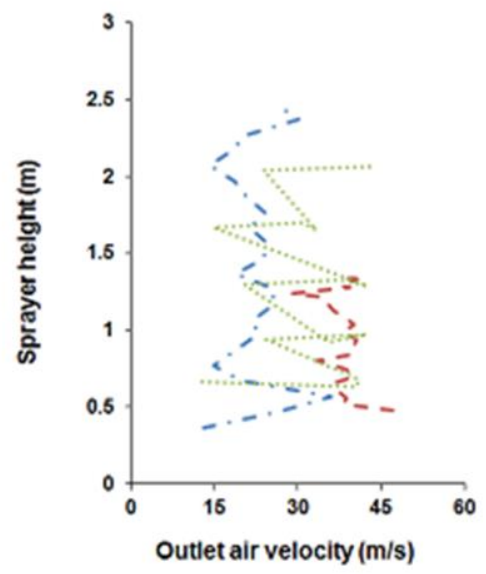

(d)

Fig. 1. The 3 orchard sprayer designs used: (a) crossflow sprayer Duoprop, (b) axial sprayer CondorV, (c) individual spouts sprayer Tango, (d) the oulet air velocity from Duoprop ( - - ), CondorV ( - - ) and Tango ( $\cdots \cdot \cdots)$ sprayers 


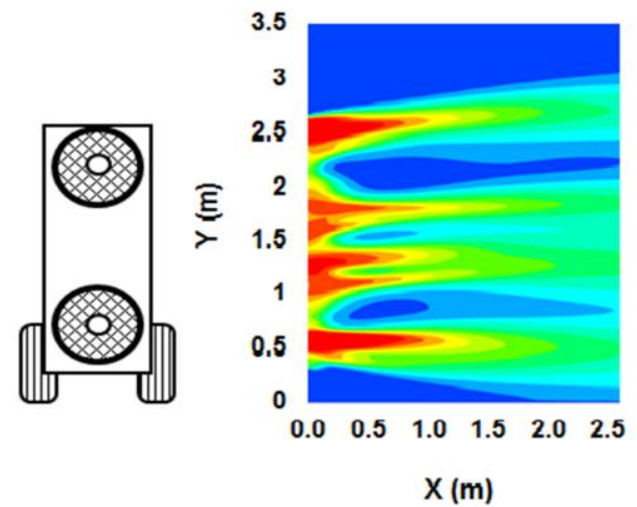

(a)

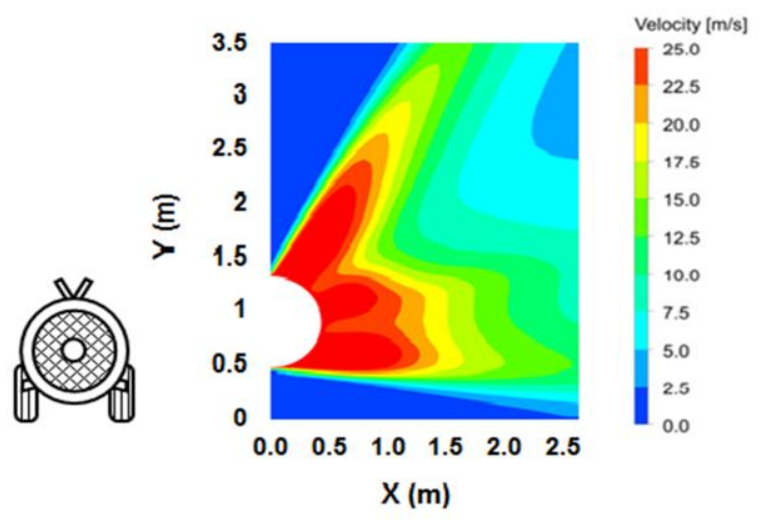

(b)

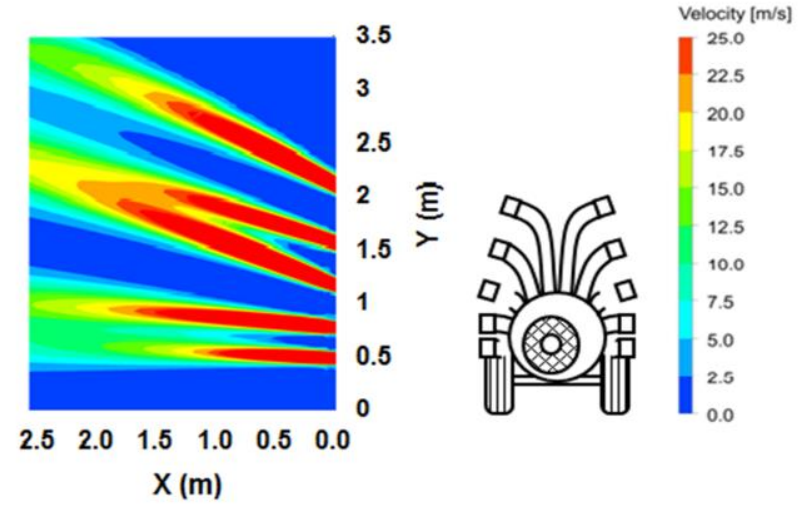

(c)

Fig. 2. The air velocity contours for the 3 orchard sprayer designs used: (a) crossflow sprayer Duoprop, (b) axial sprayer CondorV, (c) individual spouts sprayer Tango 


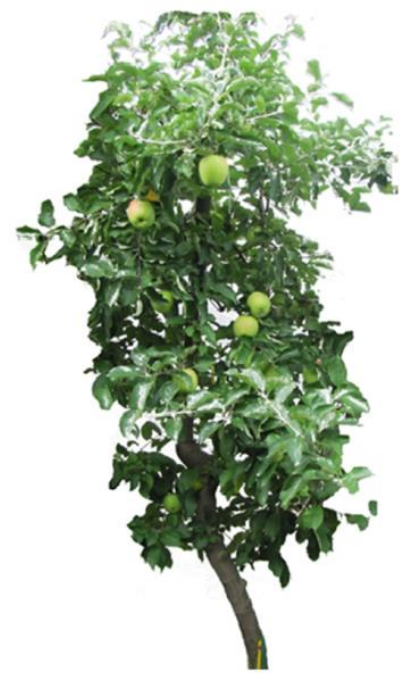

(a)

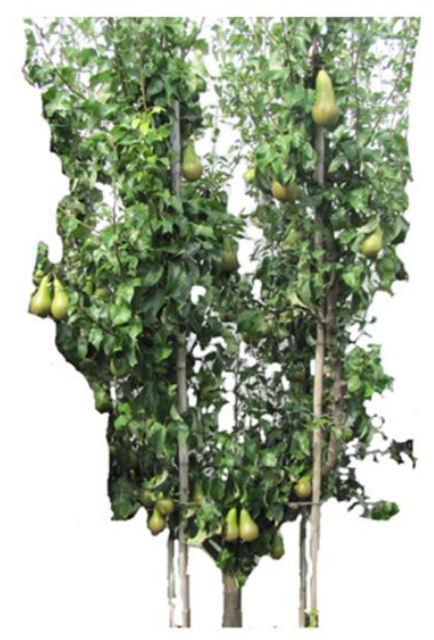

(c)

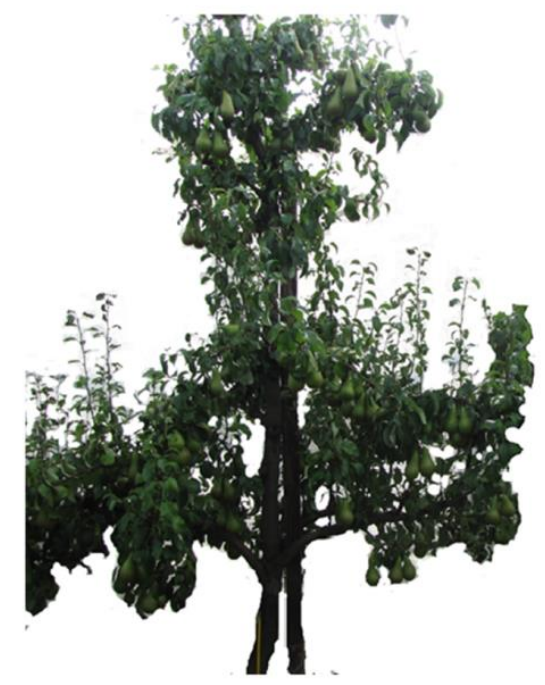

(b)

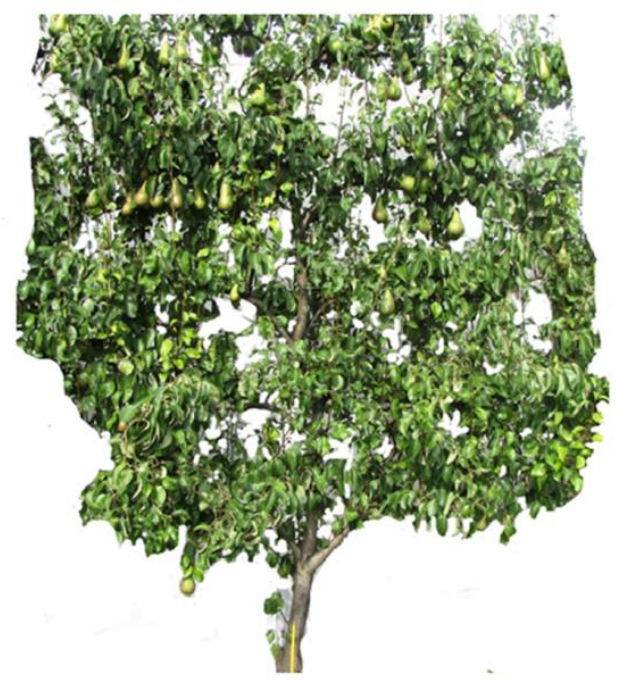

(d)

Fig. 3. The four different training systems used for the field experiment: (a) apple classical, (b) pear classical, (c) pear V-hedge, (d) pear T-hedge. 


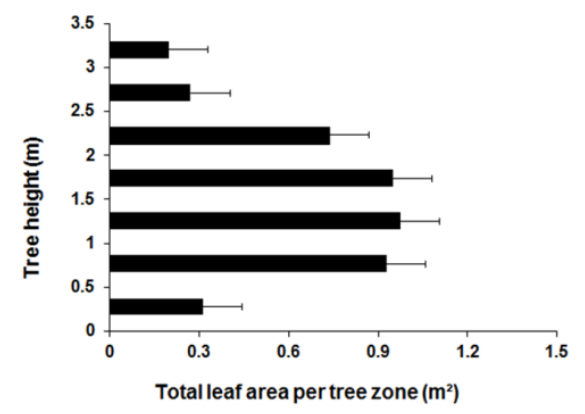

(a)

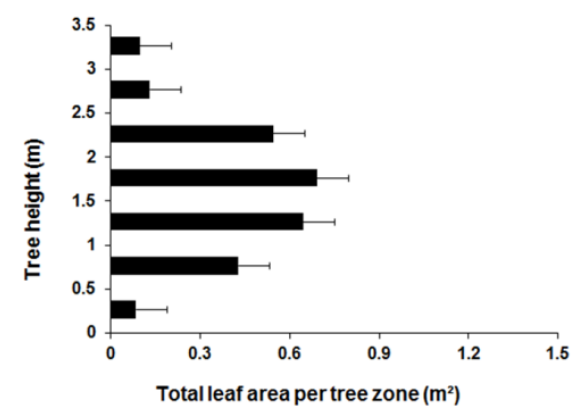

(c)

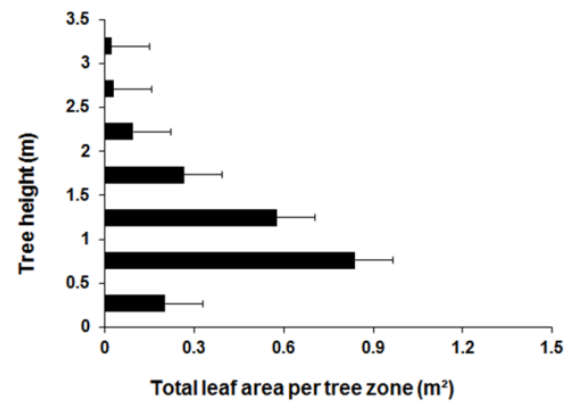

(b)

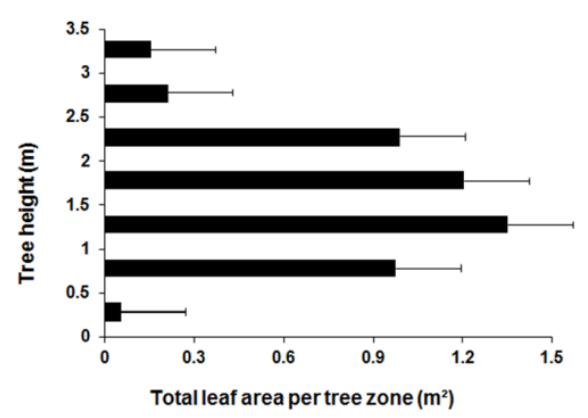

(d)

Fig. 4. Total leaf area distribution in a $0.5 \mathrm{~m}$ vertical tree zone of the 4 training systems when fully leafed: (a) apple classical, (b) pear classical, (c) pear V-hedge, (d) pear T-hedge (Error bars denote standard error). It was not possible to measure the leaf area above $3 \mathrm{~m}$ height due to accessibility restrictions on the experimental site; in this zone values are extrapolated from the top measured zone. 


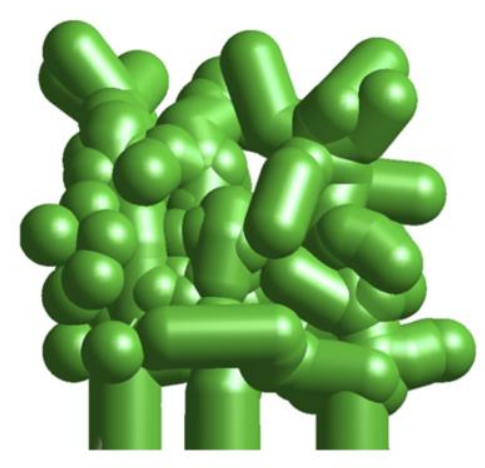

(a)

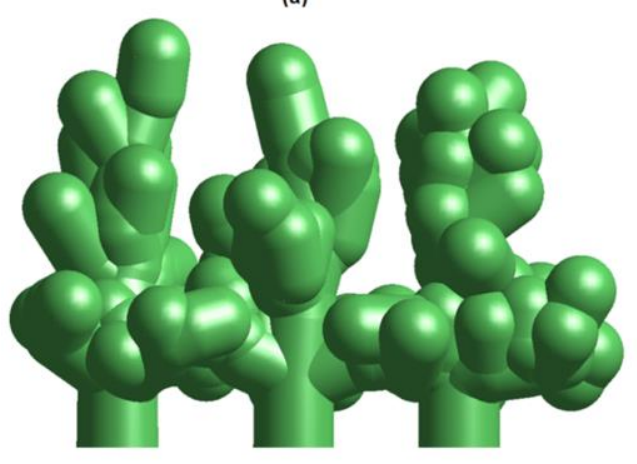

(c)

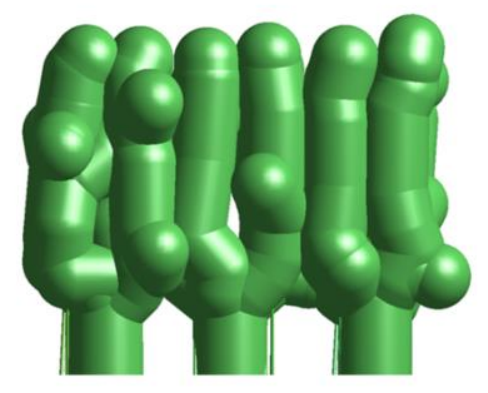

(e)

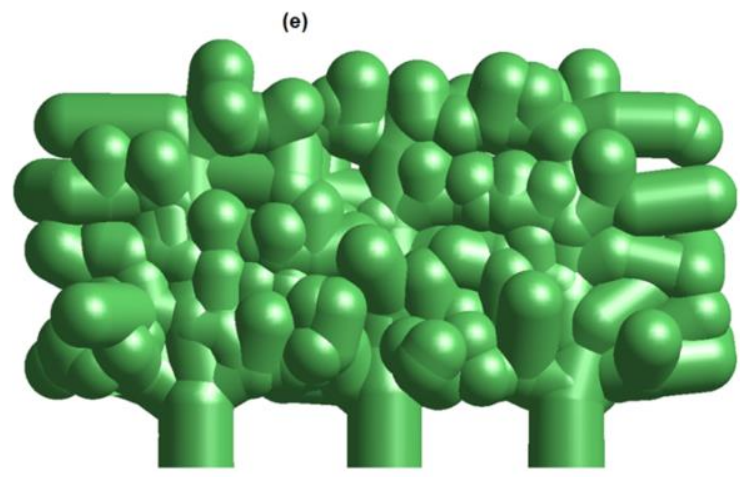

(g)

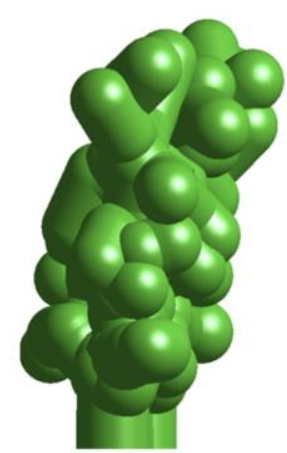

(b)

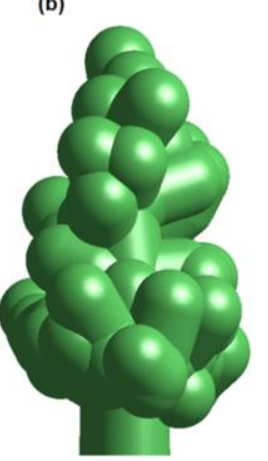

(d)
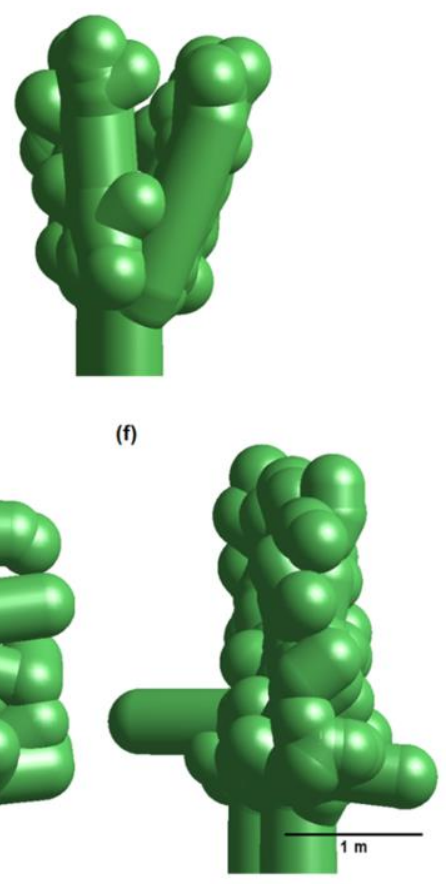

(h) 
Fig. 5. 3D model of the tree structure of the 4 training systems : (a) apple classical (frontal view), (b) apple classical (lateral view), (c) pear classical (frontal view), (d) pear classical (lateral view), (e) pear V-hedge (frontal view), (f) pear V-hedge (lateral view), (g) pear T-hedge (frontal view) and (h) pear T-hedge lateral view. The green volumes indicate the extent of the leaf cover around the branches 


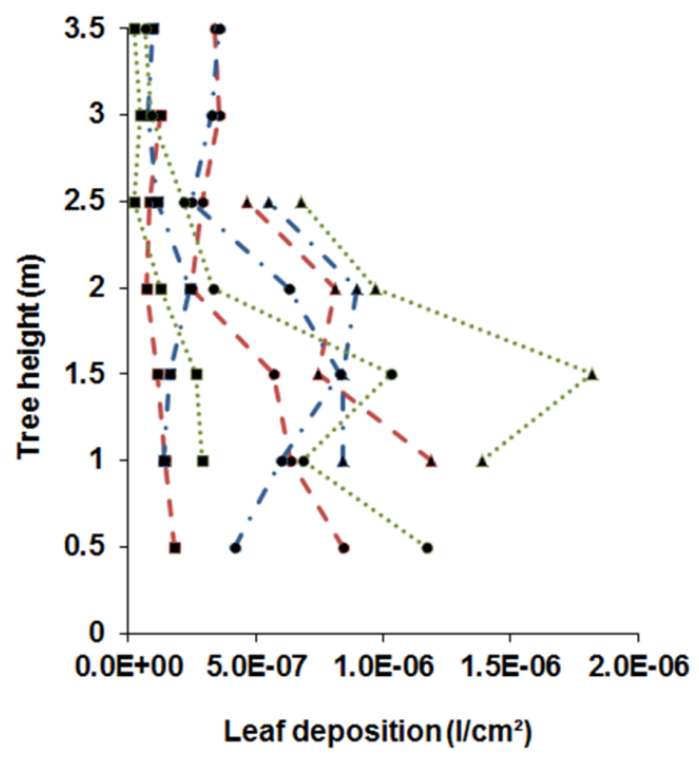

(a)

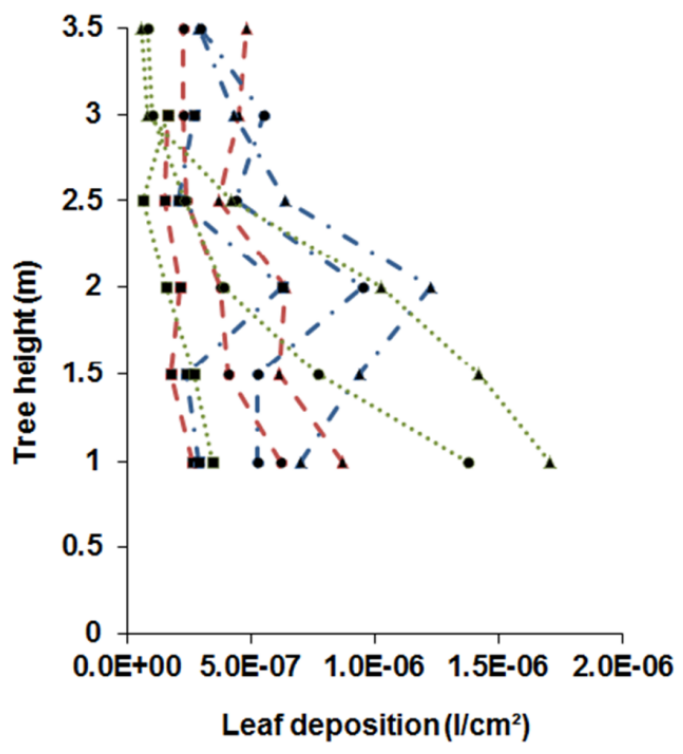

(b)

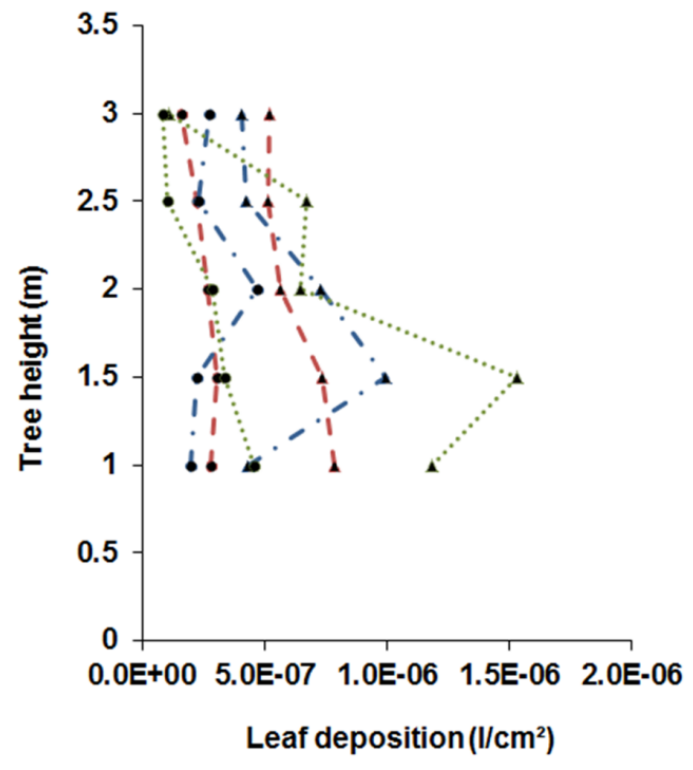

(c)

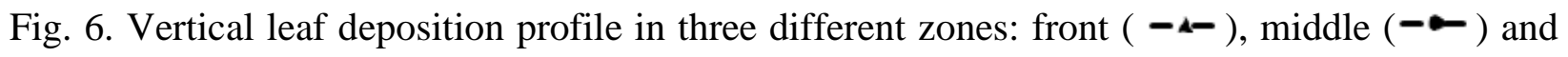
back ( $-\infty$ ) across the lateral depth of (a) apple classical, (b) pear classical and (c) pear V-hedge

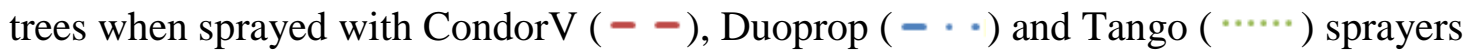




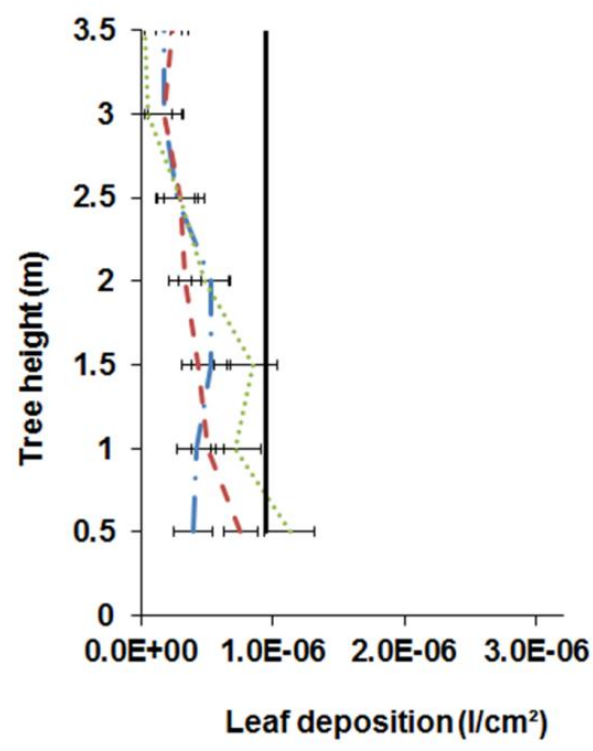

(a)

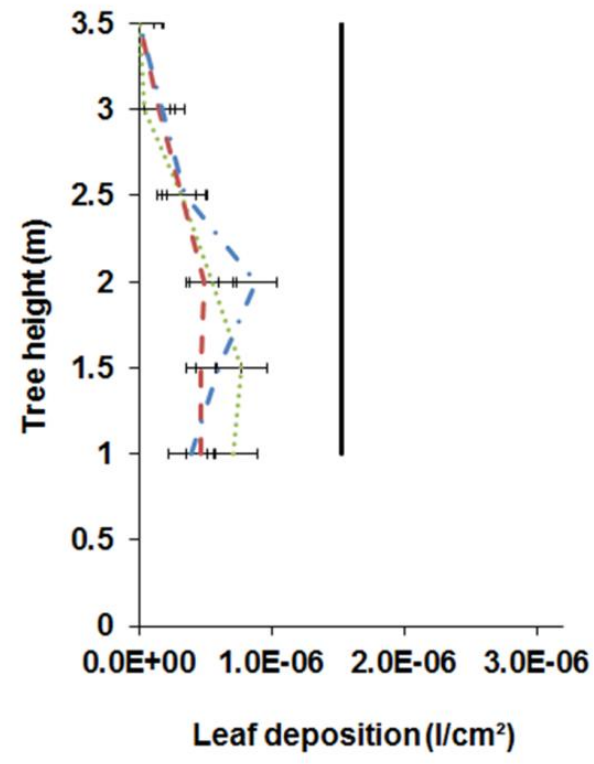

(c)

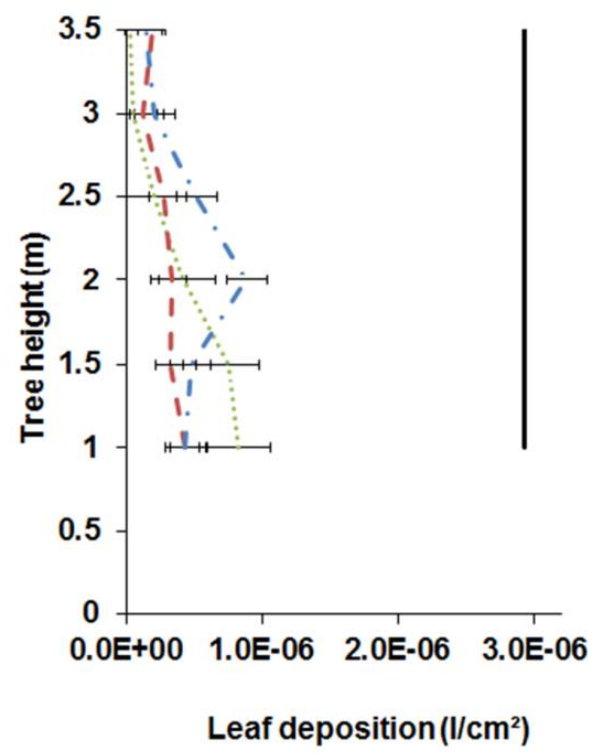

(b)

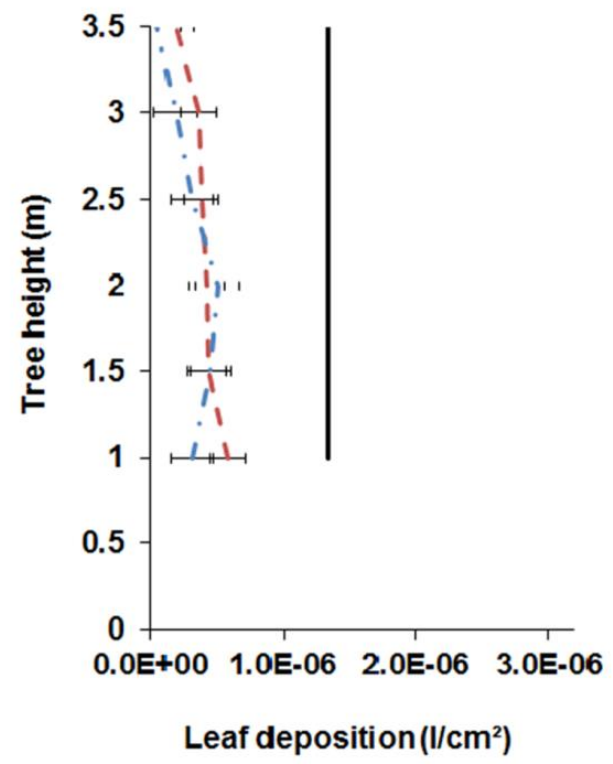

(d)

Fig. 7. Average leaf deposition profile averaged over the different depths and across the lateral depth on trees when sprayed with CondorV $(--)$, Duoprop $(-\cdots)$ and Tango $(\cdots \cdots)$ sprayers: (a) apple classical, (b) pear classical, (c) pear V-hedge, (d) pear T-hedge (Error bars denote standard error). The black solid line is the target dose on the tree for an application rate of $500 \mathrm{~L}$ 
$\mathrm{ha}^{-1}$, taking into account the total measured two side leaf area and one-sided spraying. The driving speed was $6.2 \mathrm{~km} \mathrm{~h}^{-1}$

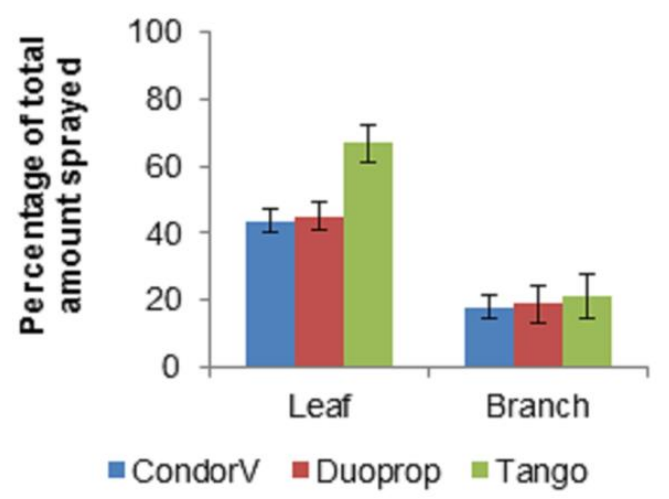

(a)

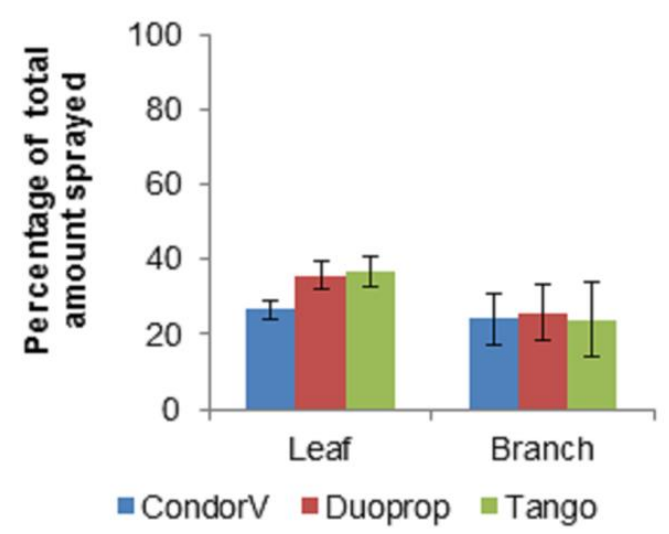

(c)

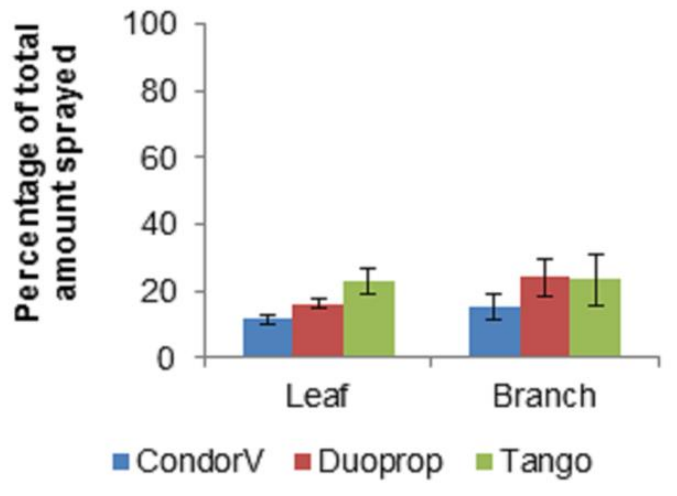

(b)

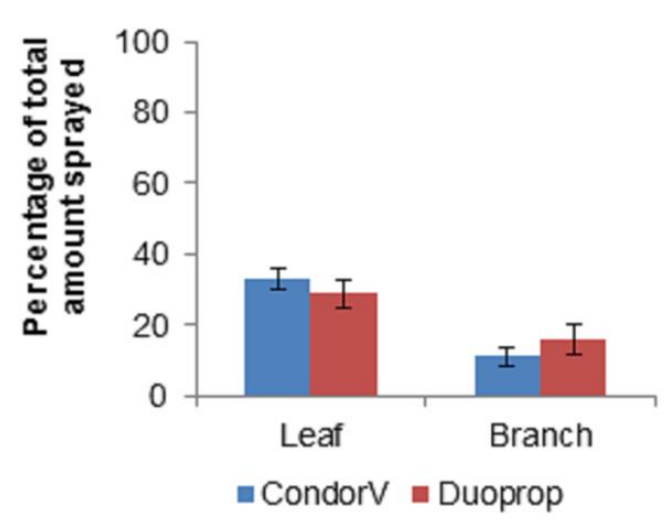

(d)

Fig. 8. The total leaf and branch deposition on fully leafed trees expressed as a percentage of the total amount sprayed (Error bars denote standard error): (a) apple classical, (b) pear classical, (c) 
pear V-hedge, (d) pear T-hedge. One-sided spraying with an application rate of $500 \mathrm{~L} \mathrm{ha}^{-1}$ at a driving speed of $6.2 \mathrm{~km} \mathrm{~h}^{-1}$

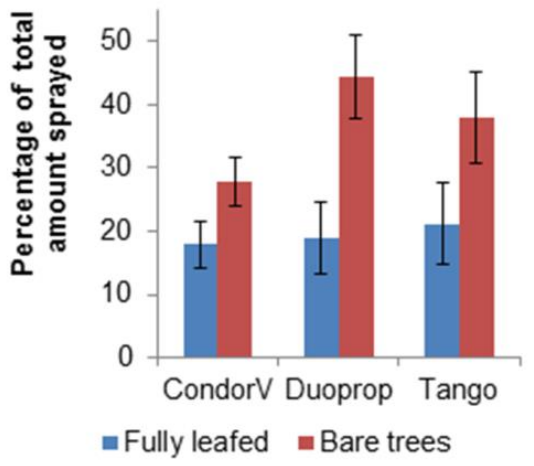

(a)

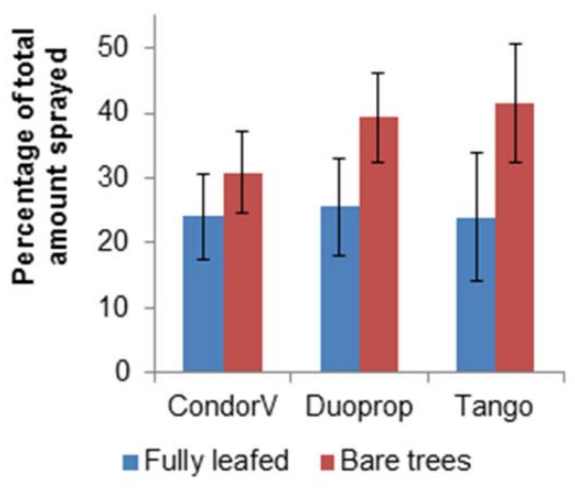

(c)

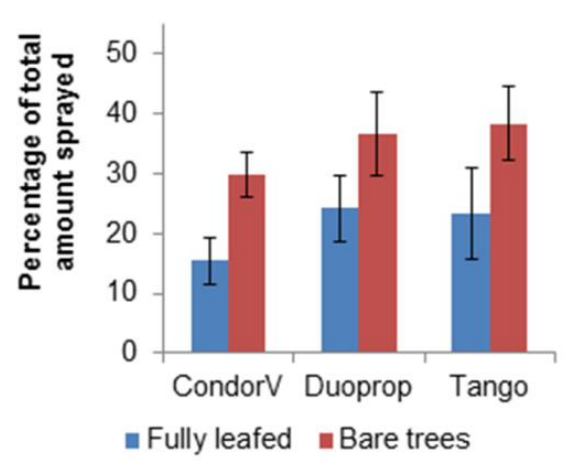

(b)

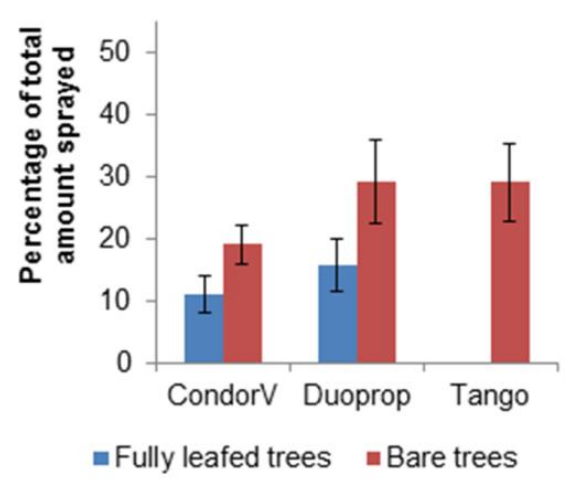

(d) 
Fig. 9. Total branch deposition expressed as percentage of the total amount sprayed for fully leafed and bare trees (Error bars denote standard error): (a) apple classical, (b) pear classical, (c) pear V-hedge, (d) pear T-hedge. One-sided spraying with an application rate of $500 \mathrm{~L} \mathrm{ha}^{-1}$ at a driving speed of $6.2 \mathrm{~km} \mathrm{~h}^{-1}$ 